\title{
Cor triatriatum in a young woman with syncope
}

\author{
J F Doyle, ${ }^{1}$ A Bessent, ${ }^{2}$ M T Dahdal, ${ }^{2}$ S W Dubrey ${ }^{1}$ \\ 'Department of Cardiology, Hillingdon Hospital, Uxbridge, UK; \\ 2Department of Echocardiography, Hillingdon Hospital, Uxbridge, UK
}

Correspondence to SW Dubrey, simon.dubrey@thh.nhs.uk

\section{DESCRIPTION}

A 28-year-old woman presented with recurrent syncope, usually precipitated by anxiety.

On examination, she had a low blood pressure of 112/72 $\mathrm{mm} \mathrm{Hg}$ with normal heart sounds and showed no features suggestive of genetic abnormalities. ECG, Holter and treadmill stress tests were normal. Transthoracic (figure 1) and transoesophageal (figure 2) echocardiography demonstrated non-obstructive cor triatriatum. A diagnosis of vasovagal syncope with incidental cor triatriatum was made.
Cor triatriatum consists of a fibromuscular membrane dividing the left atrium into a posterosuperior chamber receiving blood from the pulmonary veins and an anteroinferior chamber containing the left-atrial appendage and mitral orifice. It represents $0.4 \%$ of congenital cardiac anomalies, ${ }^{1}$ and is associated with other cardiac defects in $70-80 \%$ of cases, ${ }^{2}$ anomalous pulmonary venous drainage being the most common. Echocardiography is crucial to determine the transmembrane gradient, pulmonary vein drainage and associated defects. ${ }^{1}$

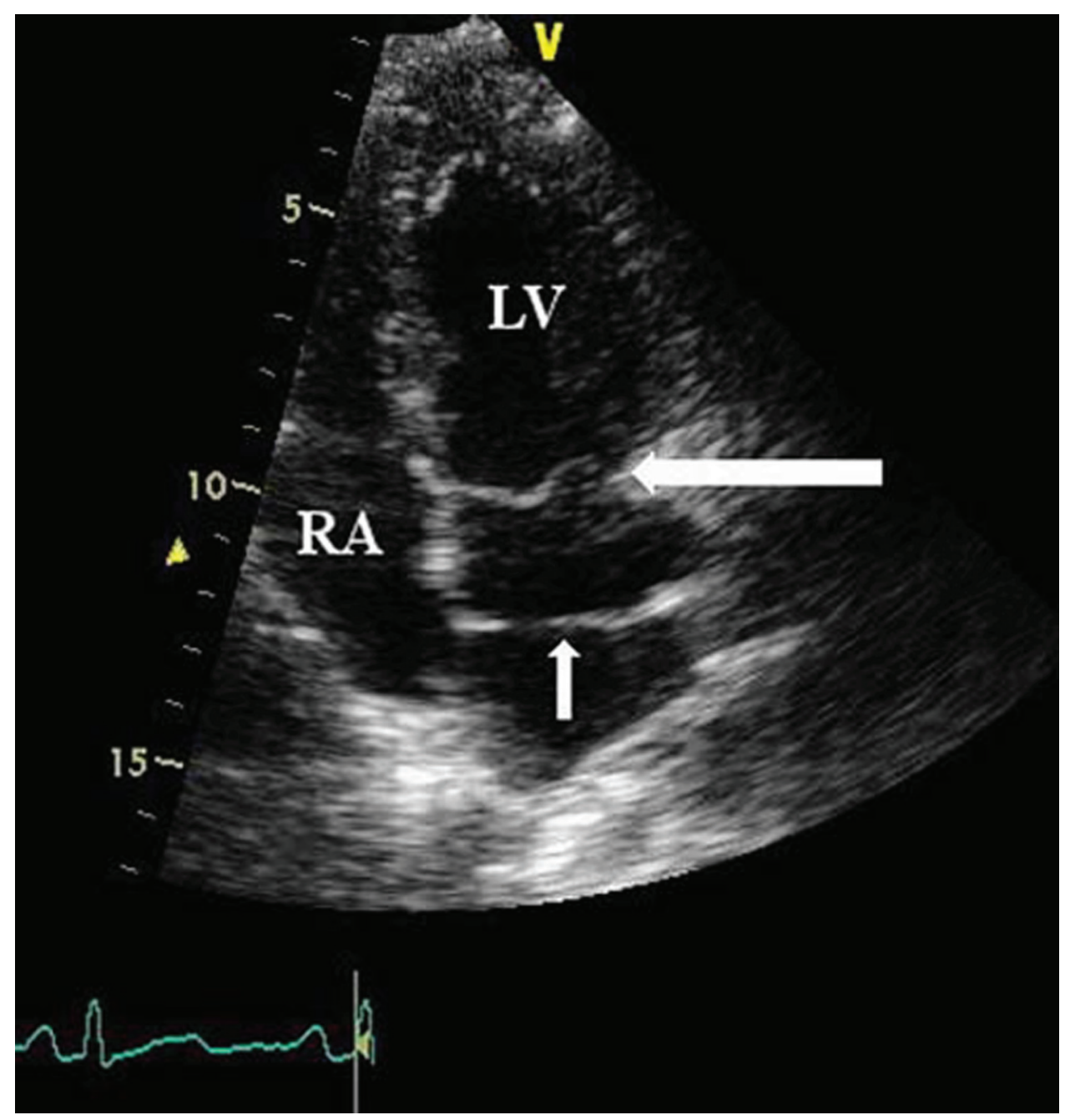

Figure 1 Transthoracic apical four chamber view showing a horizontal structure crossing the left atrial chamber (white vertical arrow). The mitral valve is at the level of the white horizontal arrow. LV, left ventricle; RA, right atrium. 


\section{BMJ Case Reports}

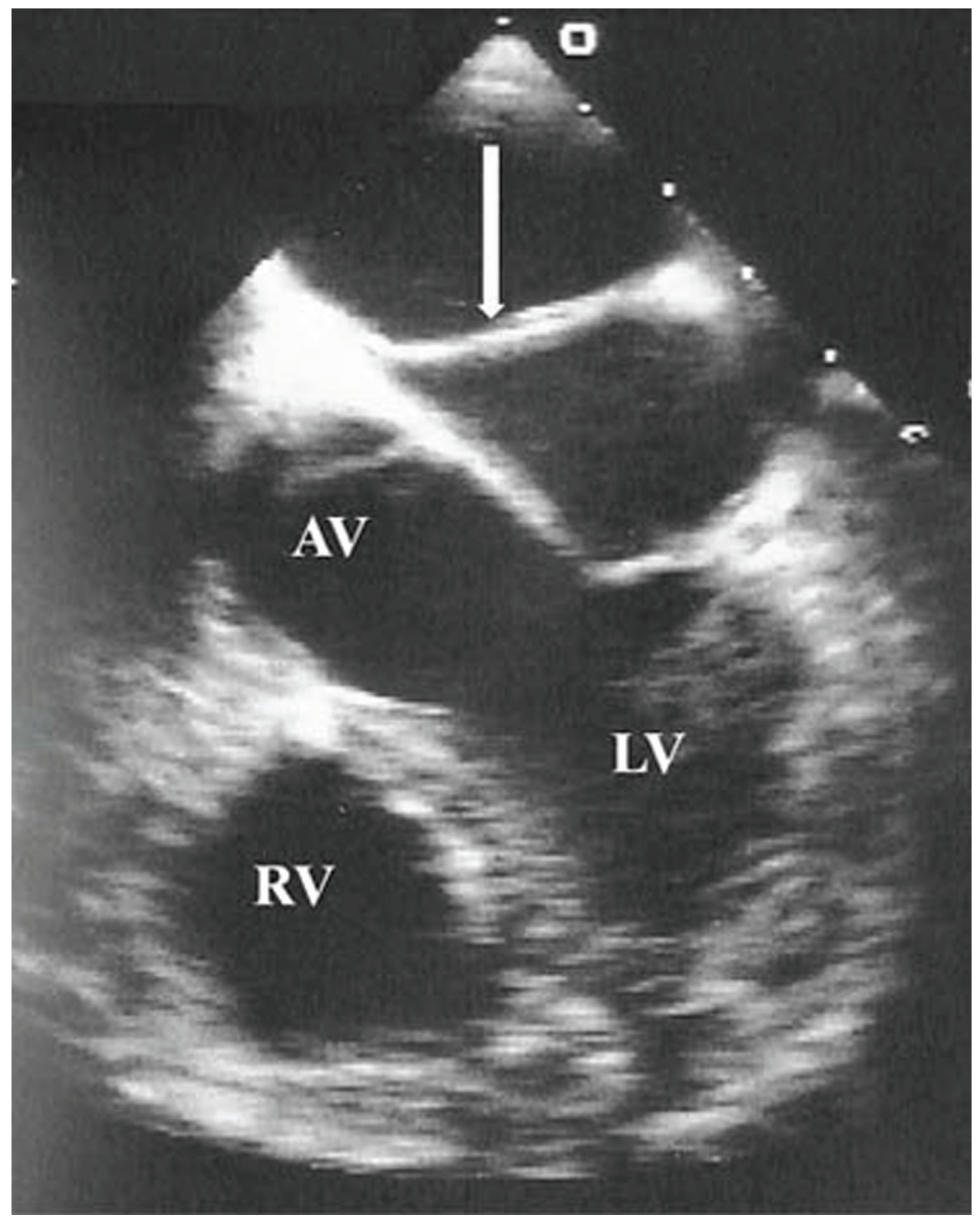

Figure 2 Transoesophageal view showing a structure crossing the chamber of the left atrium (broad white arrow). AV, aortic valve; LV, left ventricle; RV, right ventricle.

The natural history of cor triatriatum depends on the size of communication between chambers and presence of associated abnormalities. When small, it usually presents in infancy with reduced cardiac output, pulmonary venous hypertension and cardiac failure. Untreated, mortality approaches in $75 \%$ of the patients. Larger orifices may present incidentally, as described, or in young adulthood with features similar to mitral stenosis. Surgical excision of the membrane is the definitive treatment.

If present, a patent foramen ovale ( $\mathrm{PFO}$ ) or atrial septal defect permits decompression of the proximal chamber into the right atrium, with a significantly improved prognosis. Presentation in adulthood is unusual but late conversion to a symptomatic state may be caused by fibrosis and calcification around the orifice, the development of mitral regurgitation or atrial fibrillation.
Our patient was asymptomatic from her PFO. We have not recommended routine antibiotic prophylaxis but the patient was counselled to be cautious with infection, dehydration, pregnancy or surgical interventions. We anticipate annual cardiac surveillance.

Competing interests None.

Patient consent Obtained.

\section{REFERENCES}

1. Murphy D. Cor triatriatum and mitral stenosis. In: Gatzoulis MA, Webb DG, Daubeney PEF, eds. Diagnosis and management of adult congenital heart disease. Philadelphia, PA: Churchill Livingstone, Elsevier Ltd 2003;191-7.

2. Gheissari A, Malm JR, Bowman FO Jr, et al. Cor triatriatum sinistrum: one institution's 28-year experience. Pediatr Cardiol 1992;13:85-8. 


\section{BMJ Case Reports}

This pdf has been created automatically from the final edited text and images.

Copyright 2011 BMJ Publishing Group. All rights reserved. For permission to reuse any of this content visit http://group.bmj.com/group/rights-licensing/permissions.

BMJ Case Report Fellows may re-use this article for personal use and teaching without any further permission.

Please cite this article as follows (you will need to access the article online to obtain the date of publication).

Doyle JF, Bessent A, Dahdal MT, Dubrey SW. Cor triatriatum in a young woman with syncope. BMJ Case Reports 2011;10.1136/bcr.01.2011.3748, date of publication

Become a Fellow of BMJ Case Reports today and you can:

- Submit as many cases as you like

- Enjoy fast sympathetic peer review and rapid publication of accepted articles

- Access all the published articles

Re-use any of the published material for personal use and teaching without further permission

For information on Institutional Fellowships contact consortiasales@bmjgroup.com

Visit casereports.bmj.com for more articles like this and to become a Fellow 